\title{
THE CONSTRUCTION OF HOSPITALS.
}

\author{
By ALEx. CULLEN, F.R.I.B.A.
}

T $\mathrm{N}$ treating the subject of hospital construction perhaps it would be well for an architect to confine himself to the constructive side of the question, and leave the matter of administration to the care of the experienced physician. I shall, therefore, proceed at once to consider the practical elements embraced in the erection of a modern hospital.

As you are aware there are rarious descriptions of hospitals, each intended to serve some specific purpose, and these may be roughly grouped into three classes:

(1) General Hospitals for the treatment of surgical and medical cases.

(2) Special IIospitals where certain diseases are treated, as cancer; or it may be for diseases of the skin, the eye, or the ear.

(3) Hospitals for Infectious Diseases in which cases of an infectious nature such as scarlet and enteric fevers, measles and diphtheria, or perhaps smallpox, are isolated and treated, the aim being to prevent the spread of the particular discase among the community.

Of the three kinds of hospitals just mentioned, that for the reception and treatment of cases of infectious disease is, $I$ assume, the one in which the interest of The Sanitary Institute is mostly centred. While it is this class of hospital that I propose more particularly to deal with, yet my remarks will, in a number of details, apply to hospitals of all kinds; for in each type there are involved the same general principles of sanitation.

I think it well, however, not to attempt in a short paper a minute and detailed description of the many and varied points needful to bo observed in the planning and construction of a modern hospital for infectious diseases, but rather to sketch in outline the erection of such a building from the selection of a site to the furnishing of the wards.

Suppose, then, the sanitary authorities of a town of about 100,000 of a population have, after considerable pressure by the Local Government Board, resolved on the erection of a hospital for the treatment of cases of an infectious nature.

The next question that comes to be considered is the number of beds 
Alexander Culuen.
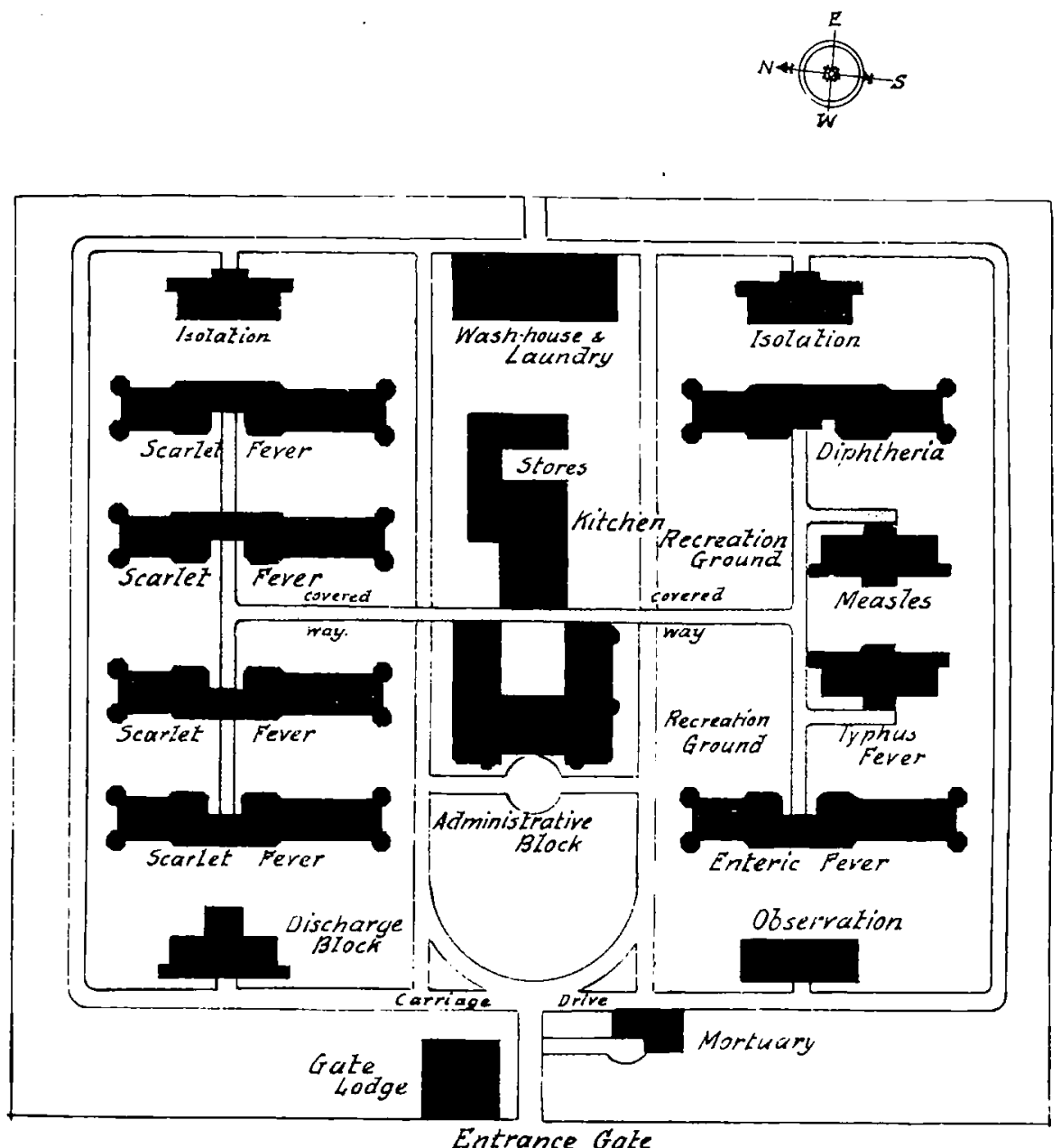

BLOCK PLAN 
The Construction of Hospitals.

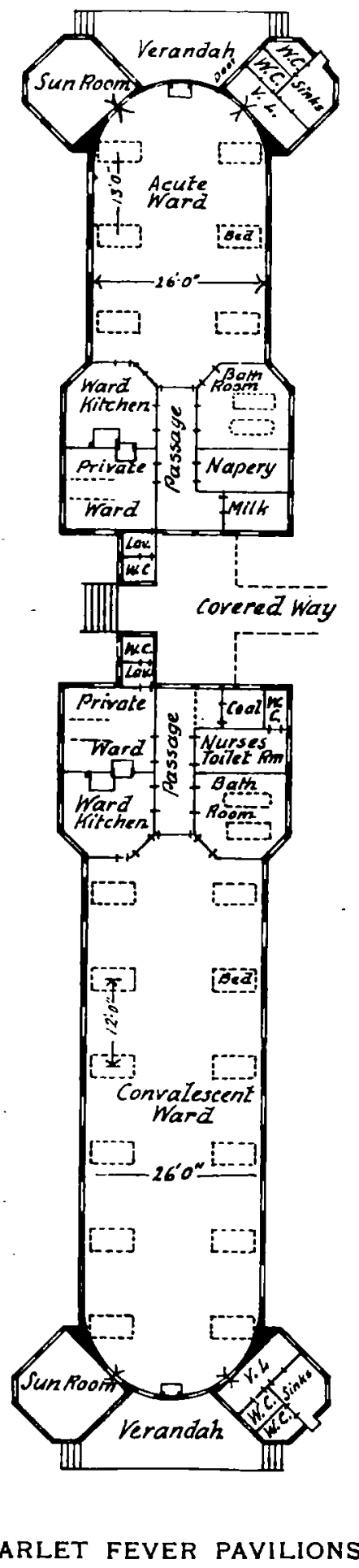


Auexander Cullen.

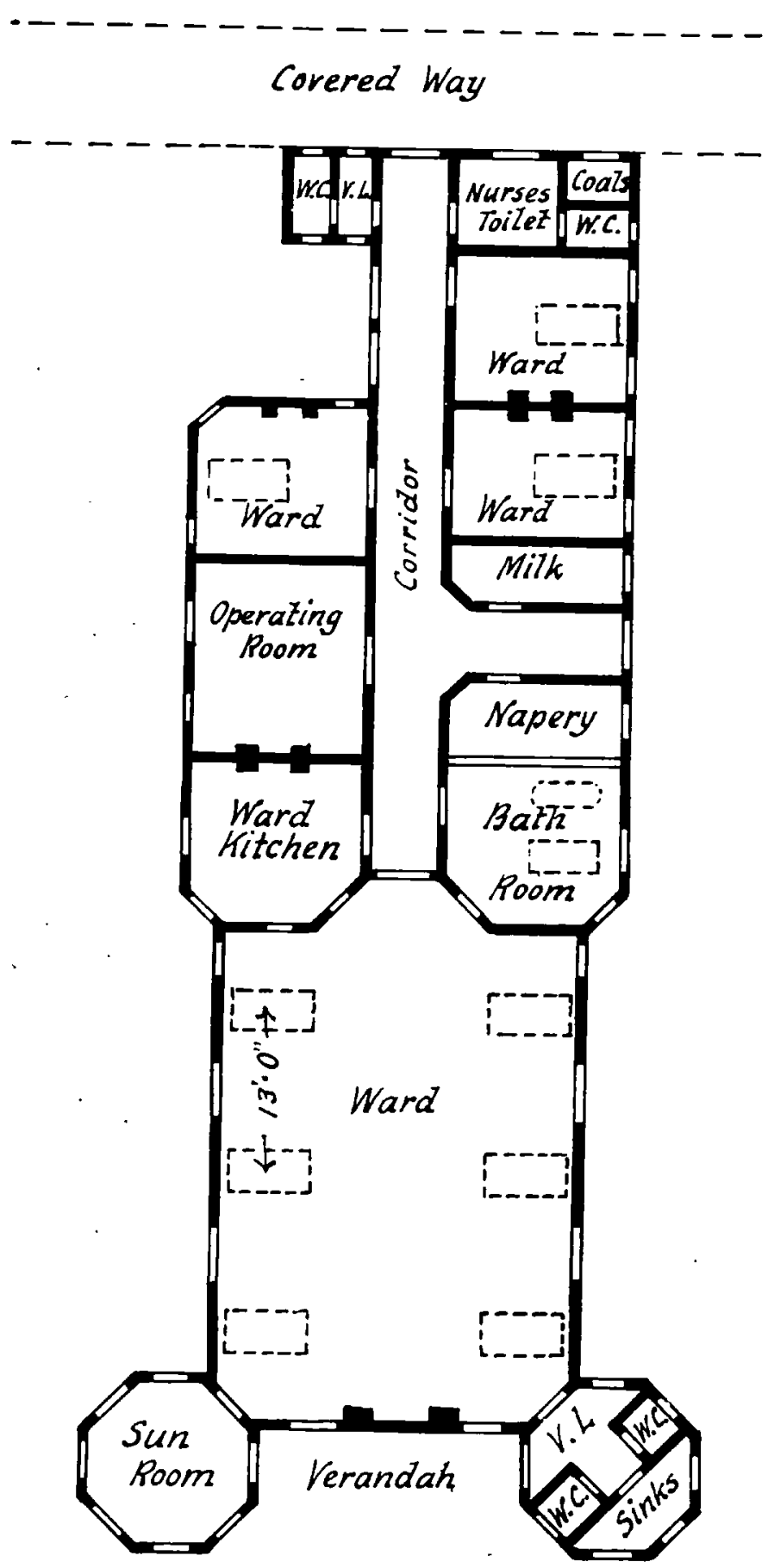

DIPHTHERIA BLOCK 
I'he Onnstruction of Hospitals.

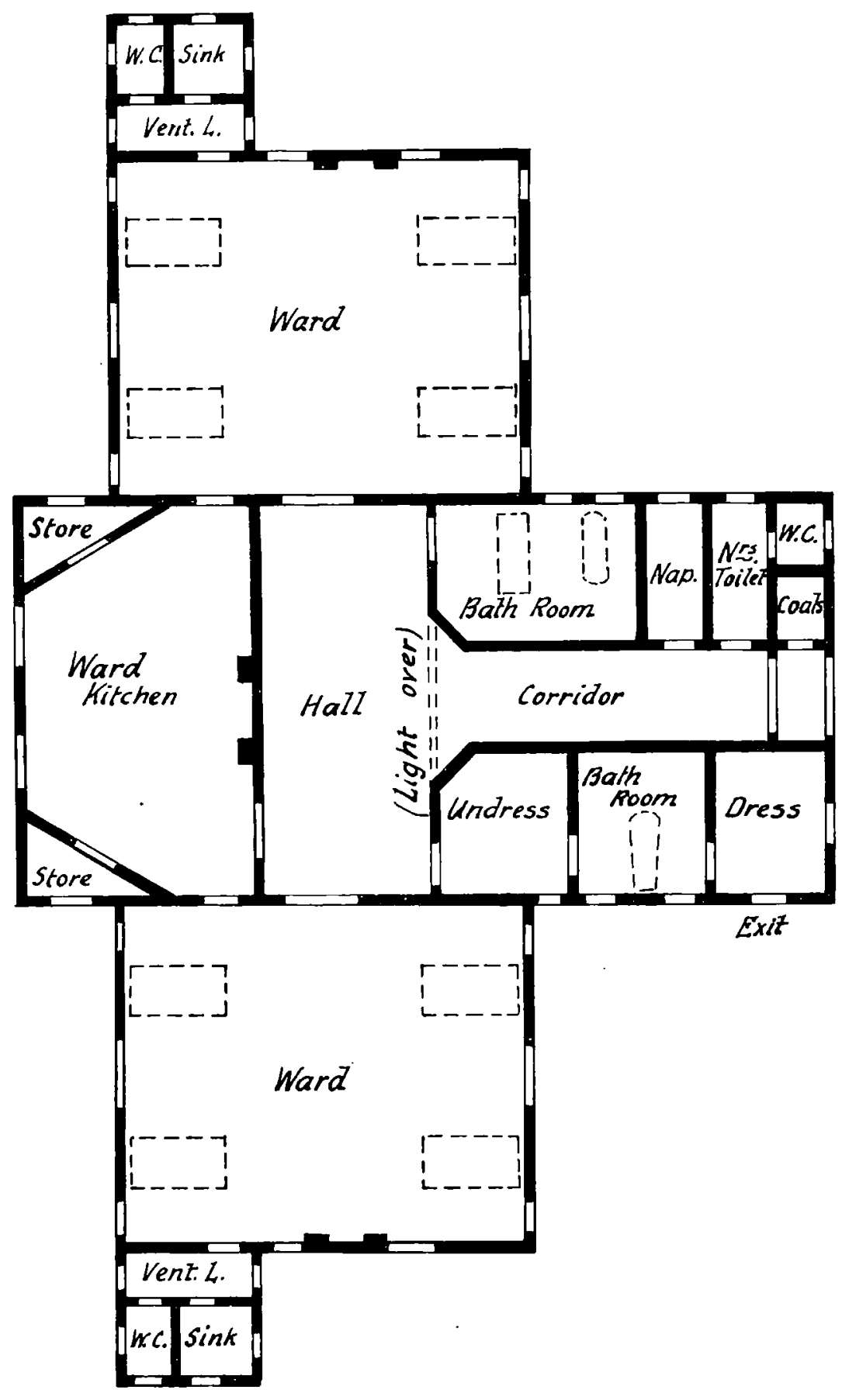

DISCHARGE BLOCK 
for which provision should be made. It is customary to provide one bed for every thousand inhabitants within the area that the particular hospital has to serve. While this may be sufficient under ordinary circumstances, it is always well to provide accommodation on an ample scale.

In order, therefore, to meet emergencies in times of exceptional epidemics, which are observed to occur at intervals of three, four, or five years, accommodation should be provided to the extent of three beds for every 2,000 of the population. In this particular case we shall assume that the hospital is to be planned on the higher standard and to accommodate 150 patients.

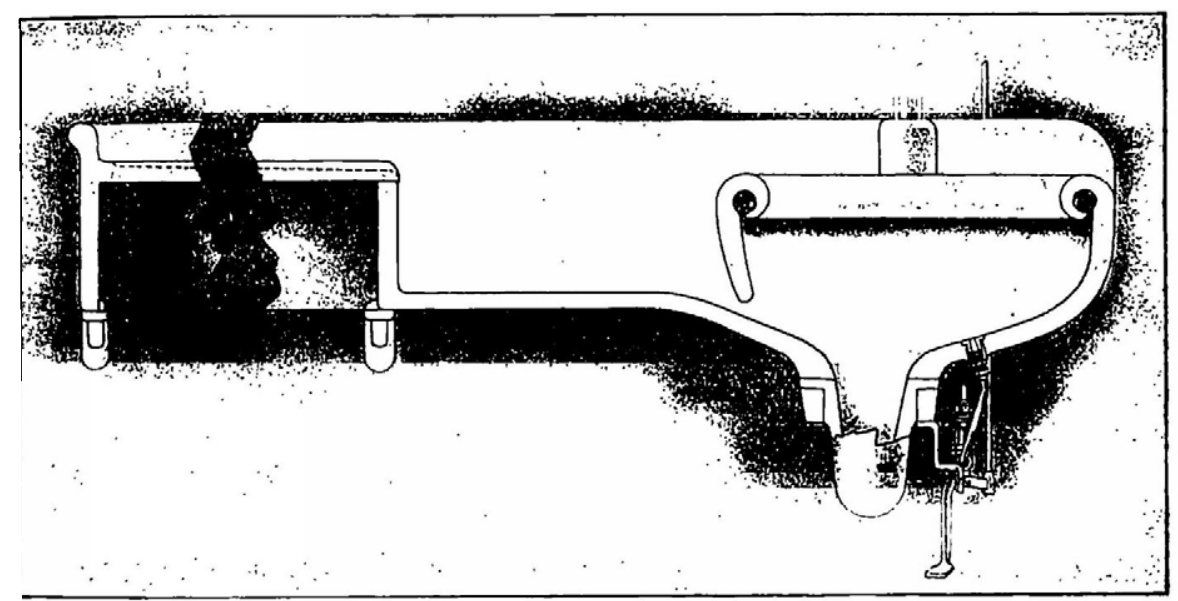

Doulton's combined mackintosh bed pan and scalding sink.

In the site of a modern hospital for infectious diseases an area of one acre for every twenty beds is considered sufficient, but in the present instance we are dealing with a model town council, and they have the wisdom to foresee the possibilities of a future extension of the buildings, and decide on acquiring ten acres of land.

This question of site is a rery important one, and it is well that the medical officer should be consulted on the matter, and in all likelihood will direct his attention to its physical conditions, such as aspect, prospect, and will enquire into the nature and extent of the sickness and the rate of mortality in the particular district.

After satisfying himself on these points, the medical officer recommends a site. It is situated in the open country yet convenient to the district

VOL. XXF. PAIT III. 
the hospital has to serve, so that patients have to be driven only a short distance. The ground slopes gently towards the south, and it is well sheltered by trees, both on the nortl and on the east sides. The soil is of a dry loamy nature, and is well under-chrained. The water level in the subsoil is fairly deep and permanent, and there are no objectionable conditions near that might lear to the pollution of the soil. There is an abundant supply of water for the needs of the hospital, and a good drainage outlet can be obtained.

The cost of the land will depend to a considerable extent on the situation, but supposing there are exceptional circumstances to be taken into account a fair value would be from $£ 250$ to $\mathfrak{£ 3 5 0}$ per acre.

The site having been fixed on, the next matter that comes under consideration is the nature and number of the diseases to be treated. On this question the medical officer will be guided by the statistics of the infectious diseases prevalent in the district more especially during epidemics. His experience also in the practical working of a hospital will indicate the extent of the administrative offices neecssary for the effective management.

Suppose then the following programme of classification with explanitory notes has been prepared:-

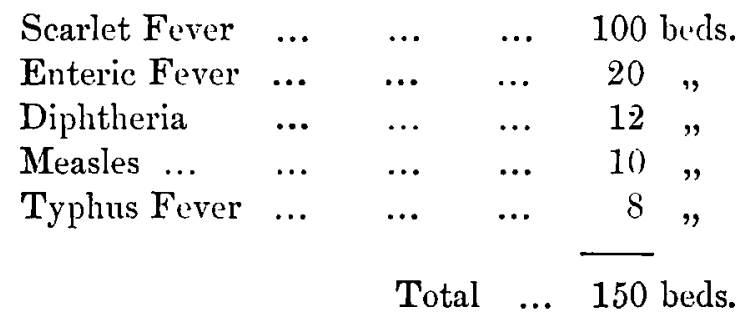

Scarlet Fever.- The accommodation for cases of scarlet fever to consist of two observation or probationary wards of two beds each. In thes. wards will be received cases considered to be scarlet fever, but in which the diagnosis was doubtful. Here such cases will be detained until the nature of the illness has declared itself.

The ordinary pavilions to provide for 72 beds divided into wards of 12 beds for females and young children and wards of 6 beds for male adults. Attached to each ward there is to be a one bed ward intended for special cases or for private patients.

Isolation Block.-Of two wards of four beds each for the isolation of cases of double infection, such as scarlet fever with diphtheria, scarlet fever with whooping cough, or scarlet fever with measles.

Discharge Block.-Divided into two wards of four beds each. To this 
block would be sent the patients believed to be free from infection. Here they would receive special bathing, and be under careful observation for a few days prior to their discharge. These precautions are intended to aroid return cases, that is, cases which occasionally occur in the households to which patients have returned from the hospital.

Enteric Fever.-The accommolation for enteric fever patients to consist of two wards, one for twelve beds the other for six beds, and attached to each a one-bed separation ward.

Diphtheria.-A block consisting of a general ward for eight beds, and four single-bed warls, besides a small room, well-lighted from the roof, where operations may be conducted. In the one-bed wards are to be special steam connections to provide a moist atmosphere for critical cases.

Measles.-A block having a six and a four-bed ward intended for the isolation of cases occurring under circumstances involving special risk of the spread of the disease.

Typhus Fever:-A block divided into two wards of four berls each. Although cases of typhus fever are not of frequent uccurrence, still it is better to provide for an emergency. This block when not in nse for its special purpose would be available as convalescent wards for enteric fever patients when that disease is prevalent.

Administrative Block.-This building should be located about the centre of the group, and convenient to the entrance gate, so that anyone calling on business, or vans delivering stores, would not go near the wards where patients are being treated. Accommodation should be provided sufficient to cope with any emergency that may arise, and the possibility of a future extension should be kept in view.

In a hospital for 150 patients there will likely be a staff consisting of a medical superintendent and an assistant, a matron, 39 nurses, 15 female servants, such as ward-maids, laundry-maids, kitchen servants, and housemaids; besides four male attendants.

The ground floor on one side of the block should be devoted to the medical officer, and the other side to the matron and nurses. On the first floor should be the sleeping accommodation for the matron and nurses, each nurse to have a separate room about $12 \mathrm{ft}$. by $9 \mathrm{ft}$. Ample bathrooms and lavatories should also be provided. Special precuntions to be taken to have the rooms for the night nurses in an undisturbed wing of the building.

The female servants to have their sleeping apartments on the second floor, but entered by a separate stair from that to the nurses' quarters. 
In the rear would be the kitchen department. The litchen should be a large apartment well lighted from the roof and thoroughly ventilated. Attached to the kitchen are to be a wash-up scullery, a regetable scullery, and a service room with a recess for food trolleys; besides the necessary stores and larders. The milk store should have an intervening lobby for scalding milk pans.

Laundry. - The laundry to be remored as far as possible from the infected buildings, with which it should have no connection by covered ways. This block may with advantage be divided into two sections, one for male and the other for female labour. In the first section will be placed, perhaps in the basement, the steam boilers, coal store, fire pumps, engine room, workshop, destructor for destroying the hospital garbage, and a steam disinfector sufficiently large to receive bedding or other large articles.

In the second section would be the washhouse and ironing room. The ironing may be common to the clothes of the staff and the patients, but there should be separate washhouses for the soiled linen of the staff. The receiving and discharge rooms should also be separate.

The drying chamber would be convenient if placed between the washhouse and ironing room, the hot air being driven into this chamber by a fan; and a fan will also be required for extracting the steam from the washhouse.

As a laundry is the place in a hospital where infected articles are gathered, special precautions should be taken. The soiled articles from the warls should be placed in steeping tanks and the tanks classificd for the different diseases.

Entrance Lodye.-This building to be placed near the entrance gate where the head male servant would reside, his wife acting as gate-keeper. Attached to the gate lodge there is to be a waiting room for friends of patients. The accommodation for the male servants to be on the upper floor of the lodge, but with a separate entrance.

Between the entrance gate and the wards there should be a waiting room for ambulance nurses, and fitted up with a hot plate and shelves for blankets.

Mortuary. - This building to consist of a mortuary and post-mortem room, a small laboratory, and a room for friends to view the body; the body, instead of being placed on a slab in the usual manner, will be laid on a bed, and the bed can be wheeled into the viewing room.

In compiling the programme I assume that the medical officer has 
been associated with the architect, and the architect will be wise if he continues this association until the general principles of the scheme are fully matured; after which the medical officer will be wise to leave the carrying out of the details to the practical architect.

The architect in preparing the plans keeps closely to the programme of classification, and connected therewith the first point to receive this attention is the ward; for the form of a ward governs to a considerable extent the planning of a hospital.

It may be taken as an axiom that where land space permits the wards are better if contained only on one floor; the pavilions are, therefore, planned one storey in height. The distribution of the several buildings on the site is a matter of the utmost importance, in order that each ward may obtain the fullest amount of sunshine.

The longitudinal axes of the several blocks are, therefore, placed north and south on the site, or, perhaps, a few degrees east of south and west of north. By this arrangement sunshine on three sides of the wards can be obtained.

The plans are based on this principle with the result that the wards are arranged on parallel lines, as shown on the block plan to which I wish to direct your attention. The space between the pavilions is 40 feet, and there is a zone of 50 feet between the buildings occupied by infected persons or things and the hospital boundary.

The communication between the several parts of the hospital is direct, and for the comfort of the staff the paths are roofed over but open at the sides.

The floor area and cubic space of a ward have to be regulated to a considerable extent by a standird set up by the Local Government Buard. The area is given at 144 square feet and the cubic space at 2,000 feet per patient. These units, however, need not be strictly applied in every case. For instance, is it not reasonable to suppose that the cubic space in an acute ward should be more than in a convalescent ward? Besides, medical authorities recommend that in cases of enteric fever and diphtheria the standard should be increased.

The width of a ward will regulate the other dimensions, but it should be noted that floor area is of more value than additional height. An ample width should be allowed for tables and fire stoves in the centre of the ward, and also to permit of the bed being kept about one foot from the wall.

Taking all these points into consideration, it seems that 26 feet is a suitable width and 13 feet a convenient height for a ward. The width and 
the height having been fixed, the only question that now remains is the distance between the beds, and this distance will determine the cubic capacity of the ward.

In the plans under consideration there is provided 12 feet of wall space - per bed for the scarlet fever convalescent wards, while in the scarlet fever acute wards and in the wards for diphtheria and enteric fever the distance is $\mathbf{1 3}$ feet. The cubic space in the one instance is 2,028 feet and in the other 2,197 feet.

The window space in a ward will be governed by the floor area and cubic contents. Experience has shown that in this country one square foot of glass is required for erery 60 cubic feet of space, but where verandahs orerhang windows or where wards are lighted only from one side the glass area should be increased.

The bathroom is at the cntrance end of the ward and is provided with two baths, one of the usual size of $6 \mathrm{ft}$. long and a smaller one for children. The baths will be rapidly filled and emptied.

The sanitary appliances are placed in a turret at one of the distant angles of the ward, and are separate therefrom by a well-lighted and rentilated lobby. Here will be two water closets and a sink room. In this room will be fitted up a combined arrangement of sinks divided into three sections :- the first consisting of a grooved slope about $3 \mathrm{ft} .6 \mathrm{in}$. long, for the cleansing of mackintosh sheets, the second of a scalding sink for washing urine bottles, and the third a sink for flushing bed pans and which will serve also as a slop sink. In the sink room there is also a small cupboard for the retention of bed pans that have to be examined by the rloctor.

At the other angle of the ward facing the south-east is a sun room, which is divided from the ward by folding doors, so that patients unable to -leave their beds can be wheeled into the room. Between the two angle turrets is a verandah for the use of patients who are able to move about.

The one bed ward is near the entrance, and has its own sanitary conveniences.

The ward kitchen is placed between the two wards, and has an inspection window into each. In this room will be a small fire range or steam closet for keeping food warm; besides a wash-up sink and a dresser. Near the ward kitchen is a nurses' toilet room and w.c., a linen store and a milk larder.

Having given a general description of the plans, let me now direct your attention to the construction, finish, and equipment of the hospital. The essential requirements are ample light and ventilation, no sharp angles 
or mouldings to catch dust, wall surface and floors of a hard nonabsorbent nature, also as little woodwork as possible; the whole so planned and constructed as to require a minimum of care or repairs. The method of construction and finish of the plans now shown is intended to accomplish this result.

The foundations will be of Portland cement concrete and the damp proof course of Caithness pavement 2 in. thick. The area under all floors will be covered with a layer of asphalte. The walls will be built of brick 16 in. thick, consisting of a 9 in. outer face, a $2 \frac{1}{2}$ in. hollow space, and a $4 \frac{1}{2}$ in. inner facing tied together with galvanised iron straps.

The ward floors will be of teak, and the surface shellacked and wax-polished. The skirting will be of the same materials as the floor, and hollowed or coved to a 3 in. radius.

The corridors and sanitary turrets will be paved with marble terazzo, while the bath rooms will be paved with incliarubber interlocking tiles.

The windows in the wards will have the lower part hung as an ordinary window and the top linged to open inwards. There will be no other projections to harbour dust, and all the facings will be rounded and keyed to the plaster. The glazing will be of polished plate-grlass, as this is preferable to double glizing with sheet-glass, for in course of time the space gets filled with dust.

The doors will have flush panels and the plainest of furniture. The standards on which the doors are hung will be checked for the doors and the wall plaster, so that no cheeks or facings will be required.

The plumbing will be executed on the most approved principle. The pipes and fittings will be exposed, and all traps will be ventilated to the roof.

The walls of bath-rooms, sanitary turrets, and corridors will be lined to a lieight of $5 \mathrm{ft}$. with white enamelled tiles. The buildings will be lighted by electricity, and there will be telephonic communication through the several blocks.

Heating and Ventilation.-The boilers for raising steam will be placed in the laundry block, the steam being conveyed in subways to a central point in each block. The steam will be led into calorifiers, of which there will be two, one for the supply of hot water to baths and sinks, and the other for the heating system.

Between the beds will be hot-water radiators, with high legs and baffle plates on front and fitted with a ventilating register, through which the fresh air will be introduced. The radiators will be fitted with valves so that the temperature in each ward can be regulated. 
The heating power will be sufficient to maintain a uniform temperature of $62^{\circ}$ in the wards and $57^{\circ}$ in the passage.

In addition to the hot-water radiators there will be open fires. The foul air will be extracted by special flues in the walls and by shafts from the ceilings, terminating at the ridge with air pump rentilators. Each outlet will be fitted with a regulating valve.

Ward Furniture.-The beds will be $6 \mathrm{ft}$. 3 in. by $3 \mathrm{ft}$, and about $2 \mathrm{ft} .6 \mathrm{in}$. high, as at that height a patient can be handled more easily. The feet will be shod with wood so as not to damage the floors. The bed will be high at the head and have three horizontal bars by which a patient may help himself in many ways.

By each bed side will be a small table of enamelled iron with plateglass top. Writing tables for the use of nurses will be required for the making up of charts. The chairs will be of plain hard wood, as no upholstered furniture is permissible in a ward.

A wheel chair with rubber tyres will be provided for conveying patients to the bath room. Screens in three leaves, each about $5 \mathrm{ft}$. $6 \mathrm{in}$. by $2 \mathrm{ft} .4 \mathrm{in}$., will be provided to draw round the bed during special examination or dressing.

Bed pans and urine bottles are better made of earthenware than enamelled iron, as in time the enamel chips off.

And now, I have finished, and no one is more conseious than myself of the number of important points in hospital construction on which $I$ have not touched; but I have tried in the short time at my disposal to give some idea of what I conceive to be an ideal hospital for infectious diseases.

Mr. Fisld (Eastbourne) asked if the convalescent ward shown on the plan was intended to be used by the same patients who bad been in the acute ward. It seemed to him it would be rather an expensive mode of construction, and also perhaps somewhat dangerous to the patients. Were the covered corridors intended to be enclosed or open? If they were enclosed he would say it would be a means of conveying infection or enclosing infection, and would connect the wards in an unsatisfactory manner. If, on the other hand, they were not enclosed, and were simply roofed, it would be a very draughty place for patients to be moved from one ward to another.

Mr. Camprell (London) said there was no doubt the arrangements shown on the side plan, and the detail upon the working plan, was, on the whole, a very good one; it was approaching the ideal, and therefore would no doubt be 
attended by very considerable cost in construction. As to the general site plan he did not know whether it was the plan of a building actually constructed or not, but if they submitted it to the Local Government Board of England there would be some little criticism to offer as regarded the particular direction the ward blocks followed. They seemed to look east and west, and the Local Government Board would insist on them being inclined to a more north-westerly and south-easterly aspect. As to the larger drawing, he noticed, there were only 18 beds shown on the diagram, plus the two private wards. It was an ideal arrangement, but considerations of cost prevailed in working out these things. Mr. Cullen showed a separate administrative arrangement for each side-that was 12 beds in one and 6 in another; only 18 in all. That would, he thought, be probibitive on the score of cost, except for the very richest communities. He liked the arrangement very much with regard to the sun room and also the verandahs. It was a much more commendable arrangement of planning than the closet buildings at the end which were so commonly adopted. He would like to know Mr. Cullen's estimate per bed of an institution of that kind. A few years ago they were able to put such a building up at about $£ 250$ per bed, but recently they had run up to as much as $£ 500$ and $£ 600$ per bed, and in one case to as much as $£ 750$ per bed. When they ran up the cost like that these luxurions institutions practically became prohibitive. It was very necessary to place the discharge block so as to prevent return cases, and he questioned very much the expediency of designing a discharge block in such close proximity to the general infected area. What they had done in East Ham was to bave the discharge block altogether away from the infected area of the hospital. They had bought an old country mansion aud utilised that for the convalescent home, so that the patients who had just left the scarlet fever wards should have about ten days' detention and probation before they were finally discharged and entirely cured. By that means the likelihood of return cases was greatly diminished. If the Local Goverument Board would insist on a separate discharge block a quarter of a mile away, even if it were only of corrugated iron, the children would be able to run about, and that would greatly reduce the likelihood of return cases.

Mr. LAмвце (Lanarkshire) said they had had experience of Mr. Cullen, and both as to cost and utility he believed that the Middle Ward Hospital at Motherwell stood unique in that country. There were some improvements in the plans before them. As to cost, the Motherwell Hospital was one of the cheapest and best to be found anywhere. Mr. Campbell had spoken about cost, and had also suggested having the discharge block about a quarter of a mile away; but he did not see how that was going to lessen the cost. As to the risk of infection, there was not much in that, as was proved by the hospital which had been erected. In Motherwell they knew the cost, and they knew also the benefit the hospital had been to the community. They bad no administration block, because they held 
that it was for those who were struck down with disease that hospitals should be erected, and there should be no palatial rooms for the administrators.

Mr. A. G. WaLlis (Glasgow) said that Mr. Saxon Snell had been unfortunately obliged to go away, but had asked him to read some comments he had written, as follows :- "Mr. Cullen advises the provision of the sinlis in conjunction with the patients' w.c.'s. I think the more modern practice is to keep them in a separate compartment with separate entrances from the ward. I have not had the advantage of seeing the plan of the ward referred to, but if as I suppose the sum room is of the same area as the sanitary annexe, it will be rather small. The whole end of the ward for a depth of 12 or 15 feet, and with both angles canted, would provide a much larger and better lighted room. Mr. Cullen suggests ordinary sash windows with hoppers at the top. That is the usual practice, but we may hope that in the near future some better form of window with fewer internal angles and grooves may be adopted. It would be quite possible to construct windows with the glass flush with the sash or casement frames. My personal preference is for casements carried down to within one foot of the floor. Doors can now be made absolutely flush both sides and veneered with wide hard wood. Referring to the beating arrangements, modern hospital practice bis got rather beyond the use of calorifiers for each separate block. It is possible and much better to carry the pipes from one central station. One is always surprised to hear that separate radiators with all their dustcollecting properties are advocated for wards. A couple of two-inch pipes carried along the walls is a much simpler arrangement. The valves can be kept outside the wards. Ward furniture can no doubt be shod with wood, but india-rubber is better."

Mr. CtLlen, in reply, said it was intended to remove the patients from the acute ward to the convalescent ward, and they had in his experience found no difficulty in so doing. He proposed that the corridors should only be roofed over. As to the position of the blocks, he did not see why the Local Government Board should not approve, because it was thought that the ideal position of a fever pavilion was that it should be a little bit east of south, and that was the position here. He saw nothing objectionable about the discharge block being where it was, because it was part of the hospital. The discharge block was entirely disconnected, and he saw no reason why patients should not be brought there and be under the care of the medical superintendent until discharged. He was aware that it was within the infected zone, but so were the other buildings. As to price, he saw nothing to prevent a hospital of that nature being built in a country district at from $£ 450$ to $£ 500$ a bed. A few years ago a hospital without the discharge block and isolation block, but otberwise of the same type, was built considerably cheaper, and the cost of Motherwell Hospital was about $£ 400$ per bed. He appreciated the criticism of Mr. 
Saxon Snell very much, but he was speaking of an entirely different type of hospital from this. Mr. Snell's remarlss applied more directly to a hospital in a city, but this one was intended to be built in the country. He did intend to put the sink into the same annexe as the water-closets, and he thought it proper to do so.

Mr. A. G. WaLlis: Mr. Snell says it is rather small.

Mr. A. Oullen said that was so, but if it had been made larger it would take away the sun from the wards, and it was better to have a small sun room than none at all. As to the windows, there were no angles or grooves. Everything was rounded and flush. With regard to the radiators it was rather objectionable to have pipes or radiators of any lind, but of the two he thought it better to have perpendicular radiators than horizontal lines of pipes. 